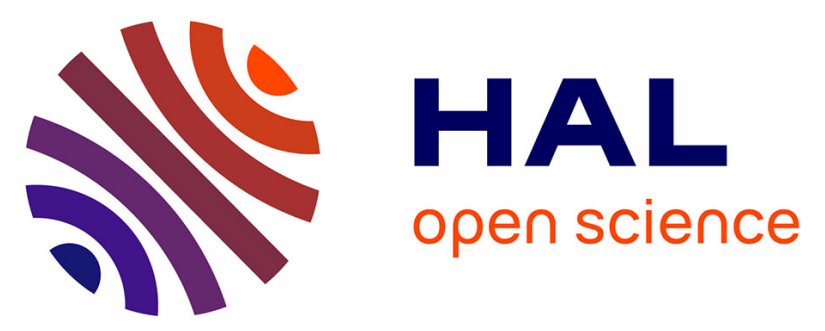

\title{
Analysis of the Intermediate Layers Generated at the Film-Substrate Interface During the CVD Process of Diamond Synthesis
}

\author{
M. Terranova, V. Sessa, M. Rossi, G. Vitali, G. Cappuccio, C. Veroli
}

\section{- To cite this version:}

M. Terranova, V. Sessa, M. Rossi, G. Vitali, G. Cappuccio, et al.. Analysis of the Intermediate Layers Generated at the Film-Substrate Interface During the CVD Process of Diamond Synthesis. Journal de Physique IV Proceedings, 1995, 05 (C5), pp.C5-879-C5-886. 10.1051/jphyscol:19955104 . jpa-00253771

HAL Id: jpa-00253771

https://hal.science/jpa-00253771

Submitted on 1 Jan 1995

HAL is a multi-disciplinary open access archive for the deposit and dissemination of scientific research documents, whether they are published or not. The documents may come from teaching and research institutions in France or abroad, or from public or private research centers.
L'archive ouverte pluridisciplinaire HAL, est destinée au dépôt et à la diffusion de documents scientifiques de niveau recherche, publiés ou non, émanant des établissements d'enseignement et de recherche français ou étrangers, des laboratoires publics ou privés. 


\title{
Analysis of the Intermediate Layers Generated at the Film-Substrate Interface During the CVD Process of Diamond Synthesis
}

\author{
M.L. Terranova, V. Sessa, M. Rossi*, G. Vitali*, G. Cappuccio** and C. Veroli*** \\ Dip. di Scienze e Tecnologie Chimiche, Univ. "Tor Vergata", Via della Ricerca Scientifica, 00133 Roma, \\ Italy \\ * Dip. di Energetica, Univ. "La Sapienza", and INFM-UdR-RM1, Via A. Scarpa 14, 00161 Roma, Italy \\ ** CNR, Ist. Strutturistica Chimica, and INFN-LNF, Lab. Raggi X, P.O. Box 13, 00044 Frascati, Italy \\ *** CNR, Ist. di Chimica dei Materiali, P.O. Box 10,00016 Monterotondo, Italy
}

\begin{abstract}
In the present work the structural characteristics of diamond films, obtained by means of Hot Filament Chemical Vapour Deposition (HFCVD), on various substrates (glassy carbon, soda-lime glass, and titanium) are correlated with the formation of different intermediate carbonaceous layers at the film/substrate interface. The surface morphology of the diamond was studied by electron microscopy, whereas the structural characteristics of the intermediate layers were investigated by means of reflection high-energy electron diffraction (RHEED) and X-ray powder diffraction (XRPD) techniques. Graphite-like and amorphous structures, respectively, were identified at the interface with glassy carbon and soda-lime glass substrates. RHEED and Grazing Incidence X-ray Diffraction measurements allowed us to determine the stratification sequence of the intermediate carbonaceous layers grown on Ti. The XRPD technique was used to study the growth kinetics of diamond, $\mathrm{TiC}$ and $\mathrm{TiH}_{2}$ layers during the coating process. The features of diamond nucleation on the various substrates are discussed with reference to the structure of carbonaceous transition layers formed at the substrate/film interface.
\end{abstract}

\section{INTRODUCTION}

The potentially new technological applications expected for diamond deposited on different substrates in the form of extended surfaces, coating and layers, have stimulated an enormous interest in the CVD techniques of diamond synthesis under reduced-P/reduced-T conditions [1,2]. The nonequilibrium conditions developed in the course of such kinetically driven processes can yield a variety of solid-state carbon species [3]. It is believed that the nucleation kinetics of specific interface structures generated during the early stages of the synthesis plays a decisive role in phase selection [4-8].

The possibility of achieving high-quality coatings, therefore, depends strongly on the control of the chemico-physical processes occurring at the substrate/film interfaces $\{9\}$.

The aim of our research work is to correlate the features of both diamond nucleation and substrate/diamond bond strength to the structural properties of the interfacial carbonaceous layers. Thus, we have submitted several different materials to a process of diamond coating by the hot filament CVD (HFCVD) technique. The present paper deals with results obtained using as substrates soda-lime glass, glassy carbon and polycrystalline titanium.

The structural analysis of the deposits and of the intermediate layers generated at the film/substrate interface during the CVD process was performed using X-ray powder diffraction (XRPD) and reflection high-energy electron diffraction (RHEED).

\section{EXPERIMENTAL}

Deposition of diamond films was carried out using hot filament assisted CVD. The stainless steel reaction chamber of approximately 15 litres and internal diameter $25 \mathrm{~cm}$ is equipped with instrumentation for pressure and vacuum measurements. The system operating pressure and the total flow rate of the gas were in the range 36-76 Torr and $100-200 \mathrm{sccm}$, respectively. The gaseous mixture $\left(1 \% \mathrm{CH}_{4}\right.$ in $\left.\mathrm{H}_{2}\right)$ was activated by a $0.3 \mathrm{~mm}$ tantalum filament wound in a spiral with an internal diameter of $0.15 \mathrm{~cm}$ and 
accurately positioned by means of a cathetometer at $5.0 \mathrm{~mm}$ above the substrate surface. The filament temperature, measured by a two-colour optical pyrometer, was kept at $2180 \pm 10^{\circ} \mathrm{C}$. A new filament was utilised during each deposition process. A thermocouple, pressed against the dc-heated molybdenum ribbon used as substrate-holder, monitored the deposition temperatures, which were between 470 and $750^{\circ} \mathrm{C}$.

The substrates were polycrystalline Ti sheets, glassy carbon [10] and soda-lime glass plates preliminary scratched under controlled conditions with a $0.25 \mu \mathrm{m}$ diamond paste and throughly cleaned ultrasonically in acetone bath.

The RHEED patterns were taken with an electron microscope (AEI EM6G) equipped with a highresolution diffraction stage. The acceleration voltage was $60 \mathrm{keV}$.

The XRPD measurements and the X-ray grazing incidence diffraction measurements were carried out by means of a Bragg-Brentano diffractometer (SEIFERT XRD 3000) operating in step-scan mode, with a secondary graphite monochromator and a $\mathrm{Cu} \mathrm{X}$-ray tube.

\section{RESULTS}

Analysis of the deposits obtained on the various substrates indicates that differences in growing conditions induce considerable changes in the film morphology, but not in the crystallographic structure. All the films have produced the same type of RHEED pattern, characteristic of the diamond Fd3m phase [11].

The main results achieved from the structural investigations of the film/diamond interface are presented in the following.

\subsection{Soda-lime glass}

Owing to the characteristics of such material (nominal composition: $\mathrm{Ca}(2 \%), \mathrm{Na}(10 \%), \mathrm{Si}(25 \%), \mathrm{O}(60 \%)$ ) the deposition experiments on soda-lime glass were performed in the temperature range $470-530^{\circ} \mathrm{C}$. Depending on the deposition conditions, the grain size of the diamond crystallites was estimated to range between 100 and $600 \mathrm{~nm}$, but in each case only randomly oriented polycrystalline films could be obtained. Figure 1a shows the morphology of a typical film. The deposits were scarcely adherent to the substrate and continuous films showed a tendency to delaminate.

The structural properties of the glass/diamond interface were investigated by RHEED after careful detachment of the outermost diamond films.

Analysis of the carbon layers found beneath the diamond deposits was also performed by Raman spectroscopy. A typical Raman spectrum collected from the substrate surface is shown in Figure 1b. The broad feature at about $1570 \mathrm{~cm}^{-1}$ confirms the amorphous structure of this carbon layer.

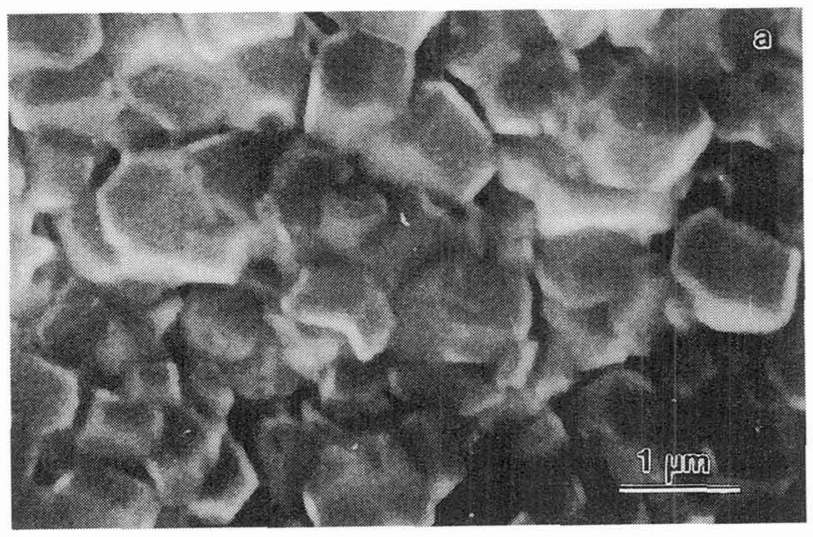

$\mathbf{a}$

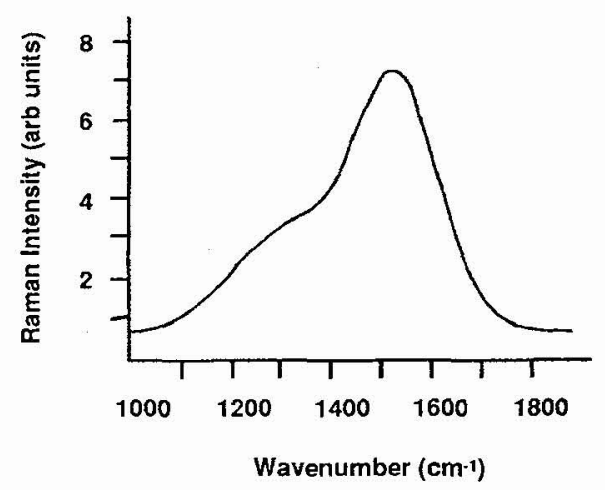

b

Figure 1: (a) SEM micrograph of diamond film grown on soda-lime glass substrate $\left(\mathrm{T}=520^{\circ} \mathrm{C}, \mathrm{td}=210\right.$ min, $\mathrm{CH}_{4} / \mathrm{H}_{2}=2 \%$ ). (b) Raman spectrum of the substrate surface after film detachment. 


\subsection{Glassy carbon}

The deposit, obtained at $750^{\circ} \mathrm{C}$, consisted mainly of large ball-shaped grains. The main size of the layer was estimated by XRPD to be about $4 \mu \mathrm{m}$. With increasing deposition time, the grains tend to coalesce, forming continuous oriented polycrystalline films (Fig.2). The glassy carbon surface was investigated by RHEED before and after the coating process. In the former case, the presence of diffuse rings revealed the quasi-amorphous structure of the material (Fig.3a). In the latter case (Fig.3b) we observed, instead, well defined rings identified as corresponding to polycrystalline graphite- $2 \mathrm{H}$ [11]. It is worth noting that this graphitic layer was not deposited onto the substrate, but was generated by a process of graphitization of the glassy carbon top surface.

For some specimens, mechanical separation of the deposited layers enabled us to reveal the presence of a f.c.c. diamond phase (space group F-43m) formed between the graphite and the diamond layers [12, 13].

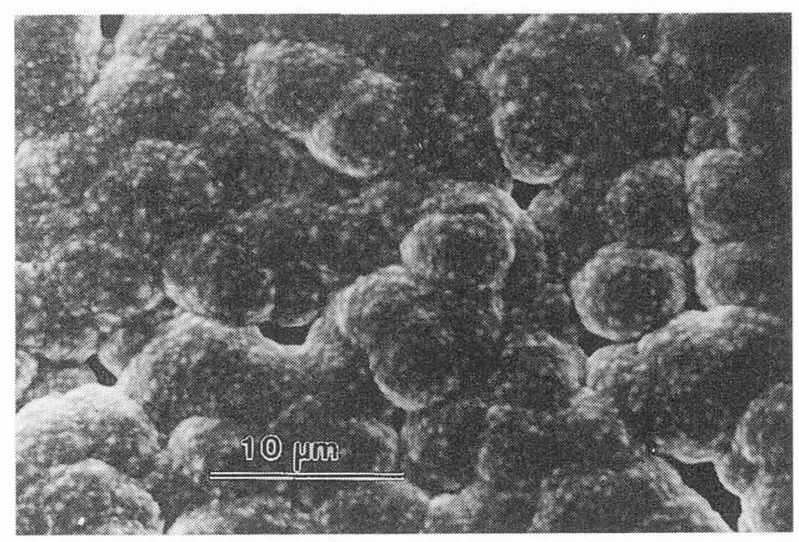

Figure 2: SEM micrograph of diamond film on glassy carbon substrate $\left(T=750{ }^{\circ} \mathrm{C}, \mathrm{t}_{\mathrm{d}}=240 \mathrm{~min}\right.$, $\left.\mathrm{CH}_{4} / \mathrm{H}_{2}=1 \%\right)$.

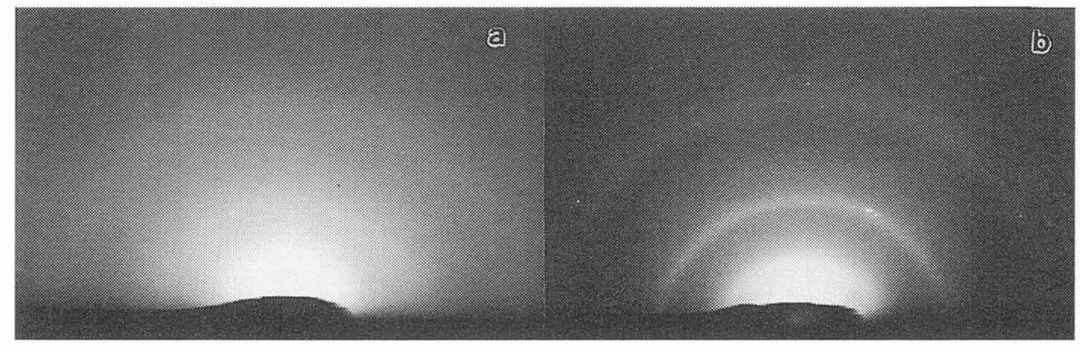

Figure 3: RHEED pattern of the glassy carbon substrate (a) before deposition (b) after film detachment.

\subsection{Titanium}

On this substrate the depositions were carried out at $650^{\circ} \mathrm{C}$, and yielded fine-grained diamond coatings characterised by a strong adherence. In Fig.4a the morphology of a typical film is clearly shown by transmission microscopy (TEM) performed on an evaporated carbon replica. The RHEED analysis (Fig.4b) performed on the film pointed out the presence of well defined preferential orientation towards the $<110>$ direction (Fig.4c). A schematic correspondence between morphology and crystallographic directions is reported in Figure 4d. 


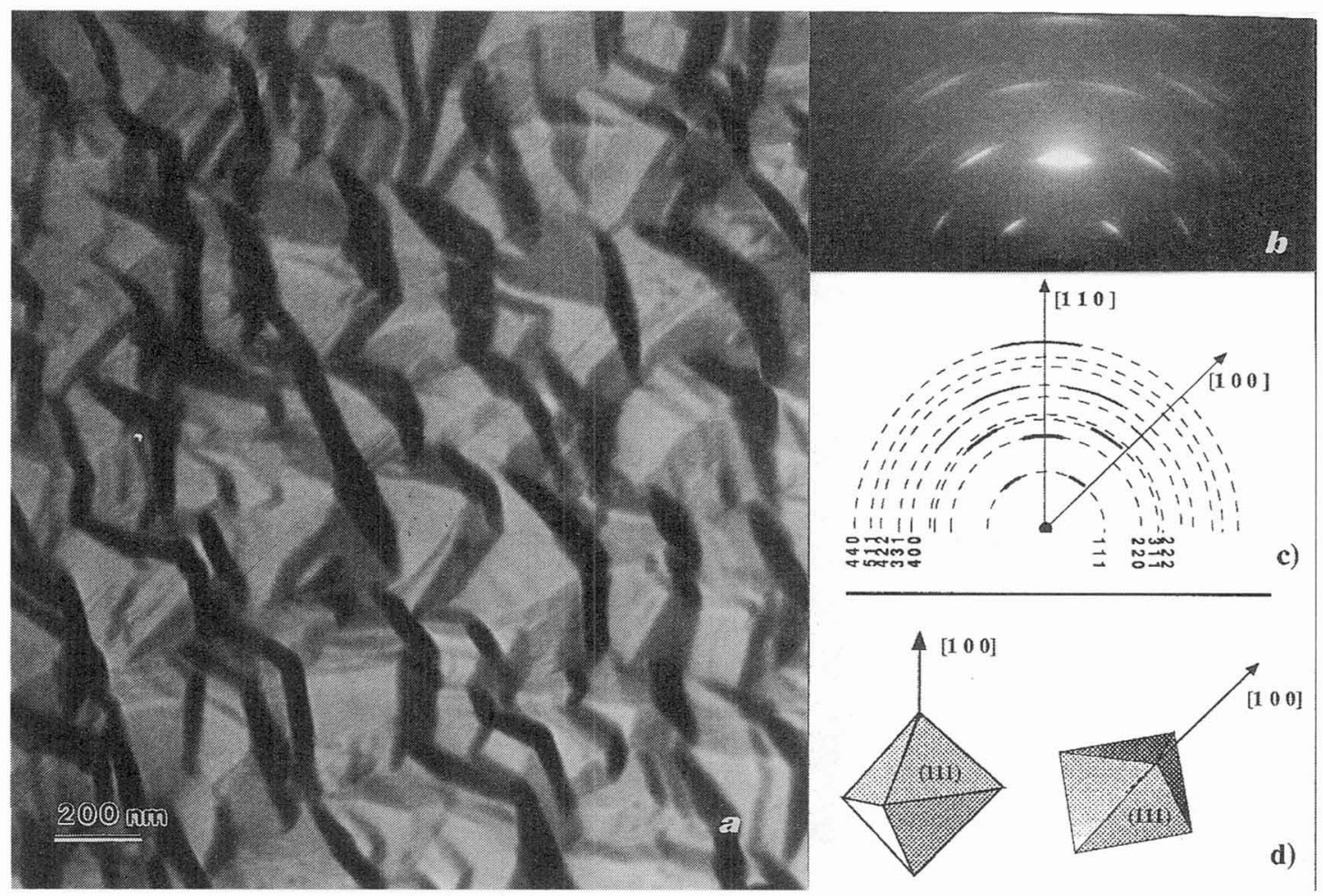

Figure 4: (a) Transmission electron microscope replica image of diamond film obtained on polycrystalline $\mathrm{Ti}$ substrate $\left(\mathrm{T}=650^{\circ} \mathrm{C}, \mathrm{t}_{\mathrm{d}}=180 \mathrm{~min}, \mathrm{CH}_{4} / \mathrm{H}_{2}=1 \%\right.$ ). (b) RHEED pattern of tha same sample. (c) Indexing of the RHEED pattern. (d) Schematic drawing showing the correspondence between the shape of single-crystal grains and their orientation with respect to the substrate.

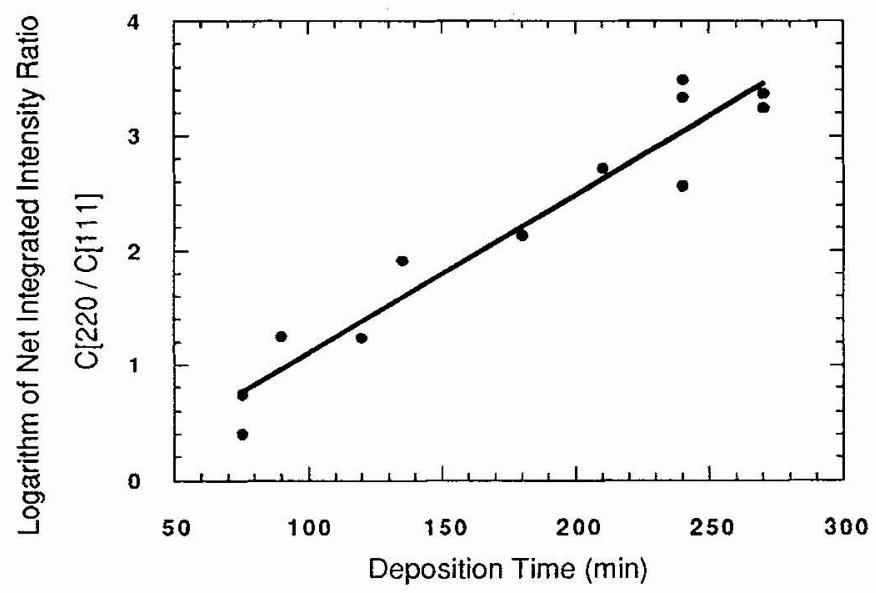

Figure 5: The logarithm of the net integrated intrensity ratios for the diamond (220) and (111) diffraction peaks vs deposition time. 
The X-ray diffraction patterns were taken in the 2-theta angular range from $34^{\circ}$ up to $120^{\circ}$, where 35 peaks, belonging to $\mathrm{Ti}, \mathrm{TiC}, \mathrm{TiH}_{2}$ and $\mathrm{C}$ (diamond), are present. Special attention was given to the intervals $34^{\circ}-46^{\circ}$ and $73^{\circ}-79^{\circ}$ where the more intense diamond peaks (111) and (220) are found

Figure 5 shows the logarithm of the net integrated intensity ratios of the (220) and (111) diamond peaks, as a function of the film deposition time. The trend indicates that a preferential orientation of the diamond crystallites towards the $\langle 110\rangle$ direction develops during the film growth. A similar trend was also found in the case of films grown on $\mathrm{Ta}$ [14] and silica glass [15].

The combined use of different structural probes allowed us to define the sequence of carbon structures deposited at the interface.

A specific RHEED investigation was performed in SAD (Selected Area Diffraction) conditions, on the border region of a masked area of the substrates. Analysis of the different patterns obtained across these areas revealed that at the onset of the process small clusters of graphite are deposited on protruded features of the titanium sheets, whereas a mixed $\mathrm{TiC} / \mathrm{TiH}_{2}$ phase is formed in the valleys. The graphitic islands became subsequently embedded in the growing TiC layer, and diamond nucleation occurs on it. A characteristic RHEED pattern in which the different phases are visible is reported in Figure 6.

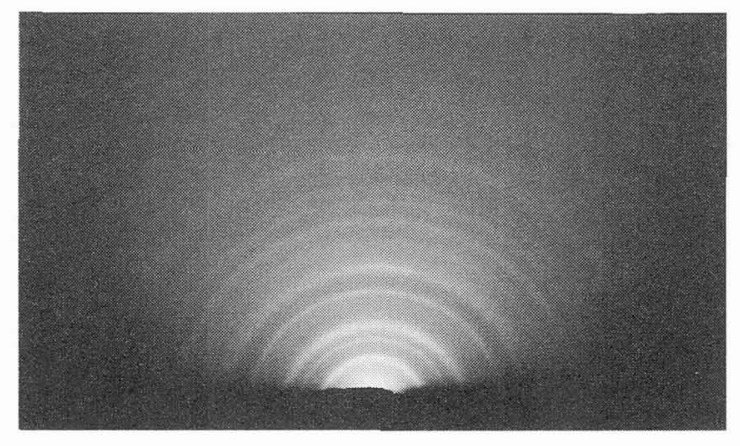

Figure 6: RHEED pattern of the Ti diamond interface $\left(t_{d}=270 \mathrm{~min}\right)$

These findings have been confirmed by X-ray grazing incidence diffraction measurements. According to this technique, a set of 2-theta scans were taken in the range $34^{\circ}-46^{\circ}$, keeping the thin film sample at a prefixed low diffraction angle $\left(0.5^{\circ}, 1^{\circ}, 2^{\circ}, ..\right)$. A typical set of spectra is reported in Figure 7 , which provides structural information on the depth of the different phases inside the film.

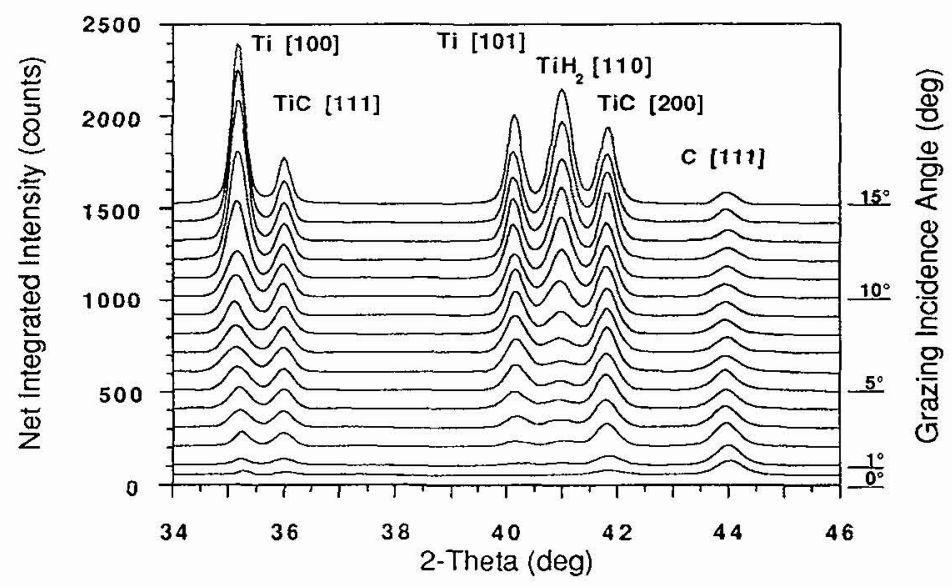

Figure 7: X-ray grazing incidence spectra which show the stratification sequence of the different phases $\left(\mathrm{t}_{\mathrm{d}}=270 \mathrm{~min}\right)$ 
A plot of the intensity of each phase vs. the grazing angle (Fig.8) put into evidence that the top film layer is formed by the diamond, followed by the titanium-carbide layer; while the titanium hydride layer is located more deeply, strictly near the titanium substrate.

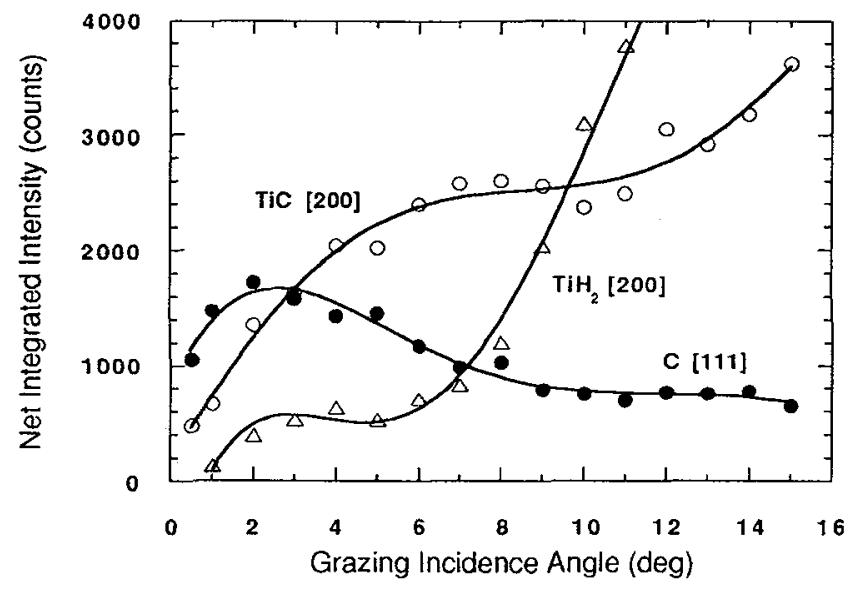

Figure 8: Net integrated intensity vs grazing incidence angle $\left(t_{d}=270 \mathrm{~min}\right)$

The growth kinetics of the carbide and hydride phases was studied by following the trend of the $\mathrm{TiC}(111), \mathrm{TiC}(200)$ and $\mathrm{TiH}_{2}(110)$ peak intensity, respectively [16]. The results, reported in Figure 9 indicate that carbide formation occurs mainly at the onset of the process, before diamond deposition starts, confirming the findings reported by other researchers [17-19]. On the contrary, the hydride formation is still effective after $270 \mathrm{~min}$ deposition, as suggested by the fact that the intensity of the $\mathrm{TiH}_{2}(110)$ reflection continues to increase monotonically with time.

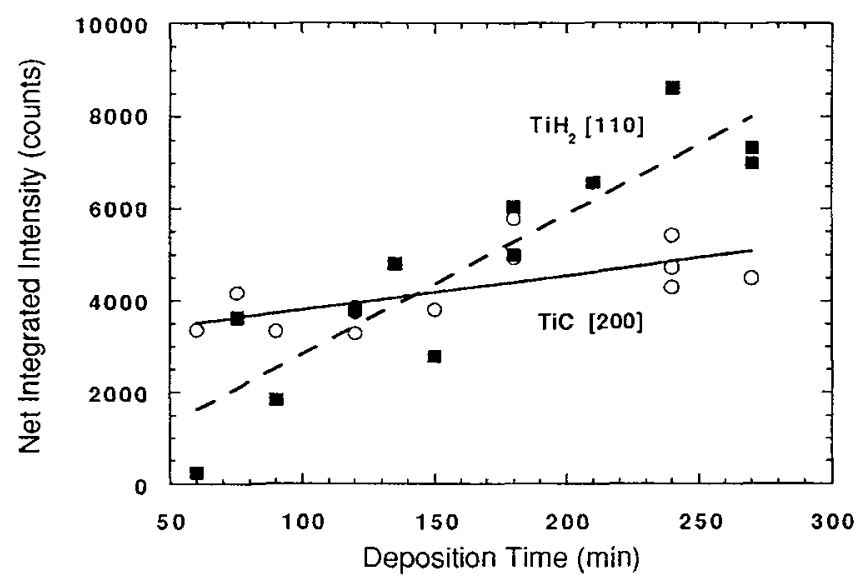

Figure 9: The TiC (200) (full line) and the $\mathrm{TiH}_{2}(110)$ net integrated intensity (dashed line) as a function of the deposition time 


\section{DISCUSSION and CONCLUSIONS}

Overall, the findings of the present experiments strongly indicate that carbon saturation of the substrate surface occurred prior to nucleation of the diamond phase. The main general difference between our samples lies in the different structure of the carbon layers beneath the diamond films.

On soda-lime glass, the Raman spectra taken from the delaminated substrate show the signature characteristic of an amorphous carbon, the structure being a disordered net of mainly sp2 sites with some sp3-bonded carbon atoms. The low temperature $\left(470-520^{\circ} \mathrm{C}\right)$ used for the diamond synthesis did not allow in this case graphitization of the solid carbon species formed on the substrate surface at the onset of the process. The poor film/substrate adhesion experienced for these samples depends on the fact that the deposits are not chemically bonded to the glass substrate.

On glassy carbon, the formation of diamond appears to follow a three-step process. Firstly, a microcrystalline graphitic layer formed by a surface graphitization process of the glassy carbon top side substrate; next, the graphite structure changed to that of a diamond polytype and, finally, the diamond $\mathrm{Fd} 3 \mathrm{~m}$ phase nucleated. Mechanical removal of the outermost deposits caused fracture of the interface between the graphite and the diamond f.c.c. layers.

With regard to the titanium substrates, at the very beginning of the deposition both carbide and graphite are generated on the metal surface. After which the growth rate of $\mathrm{TiC}$ is found to dominate, and graphite clusters became progressively embedded in the growing carbide phase. Finally, diamond starts to grow on the carbide layers. However, carbide formation does not end with the appearance of the diamond phase, nor with diamond coverage of the substrate surface, which was accomplished in the present experiments after $30 \mathrm{~min}$ deposition. This trend is in agreement with that reported by Litos et al. [18]. The same behaviour was detected for the formation of interfacial SiC layers on silicon substrates and explained on the basis of critical thicknesses reached by local carbidic islands and subsequent surface carbon clustering [6]. Following the model proposed by Stoner et al. [6], this excess carbon would act as a precursor of the diamond phase, whereas the formation of the carbidic layer would only play an intermediate role and assure a good adhesion by chemically bonding the diamond film onto the metal surface.

Under the conditions of the present experiment, the critical step of the diamond synthesis seems to be the formation of intermediate carbon layers at the substrate surface. However, a still open question is whether there is any specificity in the microstructure of these carbon phases. Further studies are being carried out in order to elucidate this fundamental aspect.

\section{Acknoweldgements}

This work was partially supported by CNR (94.00805.CT-11) and by INFN (RM2)

\section{References}

[1] DeVries R.C., Am. Rev. Sci.17 (1987) 161-174.

[2] Yarbrough A. and Messier R., Science 247 (1990) 688-696

[3] Ownby P.D., Yang X. and Liu J., J. Am. Ceram. Soc. 75 (1992) 1876-1883.

[4] Dubray J.J., Pantano G.C., Meloncelli M. and Bertram E., J. Vac. Sci. Technol. A9 (1991) 30123018 .

[5] Dubray J.J., Pantano G.C. and Yarbrough W.A., J. Appl. Phys.72 (1992) 3136-3142.

[6] Stoner R., Ma G.H., Wolter S.D., Glass J.T., Phys. Rev. B45 (1992) 11067-11083.

[7] McGinnis S.P., Kelly M.A., Gur T.M. and Hagstrom S.B., Diamond Materials 93, Dismukes J.P. and Ravi K.H. Eds. (The Electrochemical Society INC, Pennington, N.Y, 1993) 93-17, pp.153-159.

[8] Feng Z., Komvopolous K., Brown I.G. and Bogy D.B., J. Mater. Res. 9 (1994) 2148-2153.

[9] Haubner R. and Lux B, "Influence of chemical substrate interactions on diamond nucleation and growth", Proceedings of the 2nd International Conference on the Applications of Diamond Films and Related Materials, Yoshikawa M., Murawakw M., Tzeng Y. and Yarbrough W.A. Eds. (MYU, Tokjo, 1993) pp.131-138.

[10] Glassy Carbon - type V25, Atomergic Chemetals Corporation, USA.

[11] ICDD Database, card 6-675.

[12] Terranova M.L., Rossi M., Sessa V. and Vitali G., Solid State Comm.91(1994) 55-57.

[13] Terranova M.L., Rossi M., Sessa V. and Vitali G., "Phase transformation from disordered carbonaceous materials to diamond films", Proceedings of 8th Forum on New Materials, Firenze 30 June2 July 1994, P. Vincenzini Ed. (Techna, Faenza), in press.

[14] Terranova M.L., Rossi M., Sessa V. and Vitali G., Thin Solid Films 241 (1994) 340-343.

[15] Terranova M.L., Rossi M., Sessa V. and Vitali G., "Film di diamante depositati su vetri: metodologia di processo e caratterizzazioni". Proceedings of AIMAT, 2 (Trento, 19-21 September 1994) pp.653-659. 
[16] Cappuccio G., Sessa V., Terranova M.L. and Veroli C., Materials Science Forum 166-169 (1994) 325-330.

[17] Joffreau P.O., Haubner R. and Lux B., J. Refract. Hard Mater. 7 (1988) 186-194.

[18] Litos R., Haubner R. and Lux B., High Temp.-High Press., 22 (1990) 90-98.

[19] Park S.S. and Lee J.Y., J. Appl. Phys. 69 (1991) 2618-2622. 